\title{
Reflexive language and ethnic minority activism in Hong Kong
} A trajectory-based analysis

\author{
Miguel Pérez-Milans and Carlos Soto \\ UCL Institute of Education (London) / The University of Hong Kong \\ (Hong Kong)
}

This article engages with Archer's call to further research on reflexivity and social change under conditions of late modernity $(2007,2010,2012)$ from the perspective of existing work on reflexive discourse in the language disciplines (Silverstein 1976, Lucy 1993). Drawing from a linguistic ethnography of the networked trajectories of a group of working-class South Asian youth in Hong Kong (Pérez-Milans \& Soto 2014), we analyze the trajectory of Sita, a Hong Kong-born young female with Nepali background. In her trajectory, performative acts of ethnic minority-based activism emerge as key in the enactment of a given set of values, stances, types of persona and situated forms of alignment/disalignment. That is to say, Sita's enactment of activism is seen in this article as tied to a discourse register (Agha 2007: 147). As such, 'talking/ doing activism' is inter-textually linked to a speech chain network of a group of secondary school students, teachers, researchers and community-based minority activists engaged with Sita in various interrelated projects for social empowerment. Analysis of interview transcripts, online chats and multimodal artifacts shows the extent to which the coordinated formation of this discourse register proved useful in providing Sita with relevant cultural capital (Bourdieu 1986) with which she shaped her own academic trajectory, from a low-prestige government-subsidized secondary school to an elite international college. Data also point towards the need for further engagement with recent invitations to re-imagining identity and social action under current conditions of diversification (Blommaert 2013).

Keywords: discourse register, enregisterment, trajectory, identity, minority education, diversity, Hong Kong 


\section{Introduction}

In the fall of 2011, we began a four-year joint investigation at newly formed Englishbased section of a low-prestige secondary school in Hong Kong that is considered as a Chinese medium of instruction institution (the term "Chinese" refers in the Hong Kong educational context to spoken Cantonese that is written in Standard Mandarin Chinese). The school, which we call MAT, ${ }^{1}$ began in 2010 admitting students of working-class ethnic minority backgrounds to cope with declining enrollments of working-class ethnic Chinese youth. Carlos taught English and Liberal Studies there based on critical pedagogy and Miguel conducted linguistic ethnography in Carlos' classes. Following Carlos' departure from the school in the fall of 2014, we continued working for another nine months with ten students from MAT who joined a student research program we designed and ran at Methodist Community Center (MCC hereafter).

In the first publication from this effort (Pérez-Milans \& Soto 2014), we used dialogue to probe the role of reflexivity in research in our multilingual, ethnic-minority education setting. One student featured in that piece was Sita, a female student of Nepali heritage whose creative engagement with Carlos' multimodal teaching was a catalyst in our consideration of research reflexivity. When we first wrote about her, Sita was thirteen years old and had experienced familial and educational instability. Her parents divorced early in her childhood, and she bounced between living in Hong Kong with her mother and attending schools teaching in either Chinese or English, and living in Nepal with her grandmother and attending schools taught in Nepalese. As a form one student in Hong Kong in 2012, Sita painted herself as "ordinary" and "bored" and constrained by conflicts in her life (Pérez-Milans \& Soto 2014:226).

Yet by the spring of 2015 when she was seventeen years old and in form four, Sita self-identified as an "activist", and after years of socioeconomic, academic, and emotional struggles at MAT, she was accepted on full scholarship to Hong Kong Liberal College (HKLC hereafter), a prestigious two-year international school offering an International Baccalaureate Diploma. We discovered the good news via a 9-minute, self-recorded video message that she posted on Facebook soon after receiving the acceptance letter. In the following fragment from the beginning of Sita's video, she acknowledges the support of those who had been working closely with her (see transcription conventions in Appendix):

1. All names used in this article for participants and institutions are pseudonyms. 
hi everyone $\uparrow$ / my name is [Sita] / just to let you know $\uparrow$ / so today / aah / I want to make a short video / too / share / the great news that I received today $\uparrow$ / and / also to show / my gratitude to those people / uh / who have supported me / so the news is that I have been accepted into HKLC $\uparrow$ / aand / the greatest news is that I've got / a full scholarship for that $\uparrow$ / and / I really wanted to / uh / uh / show my gratitude / to those people / who supported me // so first of all I really want to thank / Mr. [Lagan] , Mr Carlos Soto / and Mr. [Pragun] $\uparrow /$ aand Dr. Miguel $\uparrow$ / for supporting me since / I was thirteen / and for providing me opportunities to explore more / outside the school / and inside the Nepalese community and outside the Nepa- Nepalese community as well $\uparrow$ / to learn / MORE / things about what's outside the school个 / and also to gain knowledge and weaknesses / uh / through those- ALSO to strengthen myself through my weaknesses / and / you all have taught me to / believe in myself / and too express what I feel $\uparrow$ / that's the most greatest- that's- that's the most important thing in our / human lives $\uparrow$ and I want to appreciate/ um/ uh / Justin $\uparrow /$ for working with us $\uparrow /$ in the research program / so I really want to appreciate for that and helping us/ uh / to do our research / so I want to appreciate Methodist Community Center who have / uh / uh / give- give- give me a space/ who have gave me a space to present myself as a young Nepali woman / uh / in a- in a- cultural aspect with my friends /

Local English and Nepali language media picked up the story of Sita's accomplishment and crafted their respective portrayals. By the former, Sita was depicted as a single student who overcame structural barriers including ethnic stereotypes, a broken home, and intergenerational conflicts, to escape her low prestige school through the help of her English teacher, Carlos. The latter emphasized Sita's individual actions and character traits, including motivation and a sociable nature, along with an understanding of and advocacy for Nepalese traditional values, Nepalese history, human rights, and education as keys for her success. But what leapt out to us was Sita as a reflexive being.

Her self-recorded speech represented the degree of self-awareness she often displayed with respect to her social circumstances and the ways to navigate them. We wondered what reflective processes Sita underwent to navigate through difficult circumstances to eventually find herself in a new social, economic, and political space. Therefore, we studied Sita's case as one in line with views of reflexivity as an emergent property of the self, an imperative form of self-governance that allows social actors to deal with social uncertainty (Giddens 1991; Beck 1992; Castells 1997; Boudieu \& Wacquant 1992). In particular, this reflexive self is now seen in the social sciences as strengthening under the conditions of so-called "late modernity", the widespread processes of late capitalism leading to the selective privatization of services, the information revolution, the weakening of the institutions of nation-states, and the fragmentation of overlapping and competing identities (Appadurai 1990; Bauman 1998). 
Initially, Sita's reflexivity seemed a clear cut exercise of what Archer calls "individual powers" (2007). In Archer's view, contemporary conditions of change force more and more youngsters to select a life path in response to incongruity and lack of continuity in their life trajectories. Faced with a liberalized and globalized labor market that pushes them to move across increasingly diversified (and trans-nationalized) contexts for further tertiary studies, youth often find that the customs, habits, routines, expectations and beliefs in which they had been socialized back in their natal communities of practice are less and less reliable when making sense and acting upon the new social conditions. As a result, Archer argues, youth tend now to engage in new meta-reflexive forms of action, as the dominant modes of socialization of the past, in which families and natal friends provided a key guide of action in the shaping of life towards their present and future, are no longer the main point of reference (2007:206-248).

However, data signaled that, in line with other critiques (Caetano 2014), Archer's accounts of reflexivity that place individual deliberations at a distance from personal networks $(2007,2010,2012)$ may not sufficiently explain Sita's case. In the post, Sita interconnects social structures and processes by reflexively examining her success in climbing up the hierarchical structure of the educational system in Hong Kong against a set of choices in which community involvement and individual assertion are discursively featured as key in her attempts to go beyond the walls of her previous school and overcome an institutional culture that she considers as excessively focused on "reciting". Thus, Sita's case offered, in our view, a relevant entry point to the study of reflexive forms of behavior whereby social subjects foreground social identities through positioning themselves in specific ways with respect to social situations and other social actors.

Concurring with Wortham's (2006) statement that "contingency happens when unpredictable configurations of resources from across multiple timescales play a role in processes like social identification" (p. 279), one could argue that having entered a network of individuals (Lagan, Pragun, Carlos, Miguel) and institutions (MCC) mentioned in her Facebook video, gave rise to a number of contingencies that shaped Sita's personal identification. In addition, the significance of this posting for this analysis lies in its performative nature, beyond content-based concerns: her act of appreciation is the instantiation of a recurrent type of social persona that was discursively made salient and co-enacted by Sita and other social actors, in response to a series of connected events. Indeed, this type of persona constituted a key symbolic resource, or a form of cultural capital (Bourdieu 1986), in the course of Sita's upward socio-academic mobility, and in the above-mentioned network of individuals and institutions. 
Based on our data analysis, we argue that recent innovations in the sociological study of reflexivity need to be carefully accommodated into applied linguistics so as to better account for the ways in which individual choices and trajectories get discursively intersected with those of other social actors, in the context of specific historical and socio-institutional junctures. In this regard, we agree with Kubota (2014) and May (2014) in their belief that foregrounding individual agency at the expense of the socio-institutional and discursive dimensions that shape it (and get shaped by it) leads to individualized portrayals of social life, as happened in the case of Sita within media discourse. Consequently, these portrayals keep us from understanding how social groups get (re-)produced, negotiated and challenged (even if momentarily) over processes of allocation and distribution of (available) socio-economic resources, in the light of current intensification of mobility and the subsequent intensification of semiotic complexity of communicative and cultural practices (Blommaert 2013).

In fact, existing research on non-ethnically Chinese working class youth in Hong Kong shows that socioeconomic stratification shapes greatly these students' socio-institutional paths, socio-emotional experiences and senses of belonging (Erni \& Leung 2014; Fleming 2015; Soto 2016), making necessary from research accounts of individuals (and groups) that go beyond those that obscure the complexity of reflexivity and of social change. Under these circumstances, we call in this article for an approach to reflexivity which heavily draws on long-standing research in the language disciplines that stems from pioneering contributions from philosophy of language (Austin 1962), linguistic anthropology (Hymes 1974; Silverstein 1976), conversation analysis (Sacks, Schegloff \& Jefferson 1974), interactional sociolinguistics (Gumperz 1982; Rampton 1995), microsociology (Goffman 1981), communication studies (Bakhtin 1986) and critical sociolinguistics (Heller 2002; Martín-Rojo 2010; Duchêne, Moyer \& Roberts 2013).

Investigating reflexivity in Sita's case requires addressing our participant's forms of action and sense-making from the perspective of reflexive language or metapragmatics (Lucy 1993), which in turn has implications as to how the relationship between language, social action and meaning is conceptualized. Such forms of reflexive discourse must also rely on ethnographic accounts of Sita's networked trajectory, beyond sociological studies solely based on series of individual interviews. These issues shall be examined in the following sections, beginning with a fuller account of our data collection/analysis, through the lens of linguistic ethnography of discourse register. After this, we return to Sita, leading to a final discussion in which we feedback to wider discussions on the implications of this research for language, reflexivity and youth in late modern Hong Kong. 


\section{Linguistic ethnography of networked reflexive trajectories}

This article is based on data collected within a linguistic ethnography (LE hereafter) spanning four years of fieldwork. LE is an interdisciplinary framework for the study of language and identity (Rampton et al. 2004; Tusting \& Maybin 2007; Creese 2008; Copland \& Creese 2015, Pérez-Milans 2016) and offers a platform for analyzing the ways in which social actors negotiate meaning and identity through language use, in the context of large historical configurations that shape (and get shaped by) these local instances of language use. Thus, this platform helps overcome long-standing binaries in applied linguistics, such as that of 'micro/macro' or 'agency/structure', suitable to the approach to reflexivity that we have outlined in the previous section.

LE shares ontological and epistemological axioms with other ethnographic and discourse-based traditions in the fields of interactional sociolinguistics and linguistic anthropology, though it differs is in its openness both to interdisciplinarity and to practical intervention (both inherited from applied linguistics). Its ontological understanding of our social world rests upon the social and linguistic/discursive turns that posit social reality as being discursively constructed, reproduced, naturalized, and sometimes revised in social interaction, in the course of large-scale historical, political and socio-economic transformations. Hence, this ontological position permits the study of reflexivity without having to build separations between individual actions and social structures. Far from being transmitted without passing through language, human deliberations are seen in this tradition as mediated by discursive interactions in which individuals engage with wider cultural conventions that are actualized in the very act of communication.

With respect to epistemological decisions about how to approach the social world empirically, LE combines ethnographic and linguistic perspectives in ways that place instability, difference and mobility at the centre of analysis. Rather than working from presuppositions about fixed mechanisms of social relations that originate in stable and abstract political and economic structures that shape local forms of social life, LE privileges empirical documentation of the ways in which social actors negotiate meaning and stance in response to the increasing uncertainty, discontinuity and lack of sharedness brought about by the institutional, socio-economic, sociolinguistic and cultural conditions of late modernity. Analytically, this orientation involves fine-grained methods for data collection and analysis of audio- or video-recordings and detailed transcriptions of interactions. Influenced by similar work in the field of linguistic anthropology (Wortham 2006), LE researchers work with each recorded and transcribed interaction as part of a 
web of social activities that participants develop in the course of their trajectories, in interaction with the trajectories of other material artefacts and discourses being produced and circulated in the field.

Based on this combination of linguistic and ethnographic perspectives, our data corpus includes: audio/video recordings of interactions in classrooms, concerts, parks, lunches, parties, field trips, and research training sessions at MCC ( +200 hours); field notes ( 3 notebooks, +50 shared electronic files); classroom materials ( +100 sheets); school's institutional documents ( +50 sheets and leaflets); online practices (2 Facebook groups and 1 Whatsapp group, totaling +100 group conversations; Tumblr pages, totaling +100 multimedia files); photos ( +500 files); interviews ( +20 hours); questionnaires $(n=40)$; media coverage involving our participants (online and print media, totaling +50 files); and our participants' self-recorded events ( +1000 multimedia files).

The analysis of Sita's reflexive practices is multi-sited (online and offline) and trajectory-based, taking into account her situated experiences across interlinked communicative genres and social settings in the context of her social network. Hence, in this article we follow a LE sensitivity with the aim of: (1) understanding social actors' reflexive experiences vis-à-vis the wider sociocultural and economic transformations (and related forms of inequity) associated with late modernity; (2) expanding the analytical attention beyond only normative institutional frames of action in fixed space-time locations; and (3) describing the discursive and network-based emergence of cultural (i.e. conventional) models of action.

Accordingly, we assembled an analytical toolkit informed by the notions of discourse register and enregisterment (Agha 2005, 2007), interdiscursivity (Silverstein 2005; Agha 2005, 2007; Wortham 2005, 2006), and discursive spaces (Heller 2007). Discourse register and enregisterment allow us to empirically describe metalinguistic or metapragmatic activity whereby individuals orient their attention to language form in order to typify the attributes of language, its users and the activities accomplished through its use. More specifically, these two notions focus on the processes whereby semiotic repertoires (including linguistic and non-linguistic signs) are mobilized by actors to create, index and further re-appropriate conventional models about social situations and types of social persona or social identities.

Interdiscursivity shifts the focus from the analysis of isolated speech events to describing linkages between speech events across space and time, thereby shedding light on the ways in which individual forms of alignment and identification emerge from patterned trajectories of socialization connecting social actors, networks and communicative encounters. The linkage between speech events can be traced back both ethnographically, by pointing out the consequences of certain events for participants' access to future ones, and discursively, by identifying 
persistent denotational or performative meanings that are recurrently taken up and negotiated across a chain of encounters.

Finally, the notion of discursive spaces provides a bridge between processes concerned with reflexive discourse and wider institutional and socioeconomic processes of structuration. It draws our attention to the interrelation between institutions, language and unequal distribution of resources - understood in a broad sense as material, symbolic, linguistic-semiotic and identity resources. Thus, institutions are seen as spaces where actors engage in a great deal of discursive and ideological production to legitimize the sheer existence of the organization, its mission and social goals, as well as the identities, and social and moral categories that are constructed and emerge out of such discursive and ideological processes. Therefore, research investigating networked trajectories of reflexive discourse needs to take into account the ways in which normative forms of knowledge (i.e. what counts as appropriate forms of contribution) and moral categorization process (i.e. how participants position themselves and others as "good" or "bad" with reference to which types of persona) get constructed and negotiated in daily communicative arrangements discursively, in intersection with institutionalized organizational logics.

So far we have outlined the academic discussions and interlocutors relevant to this article, as well as the interdisciplinary mix of ontological perspectives and epistemological traditions from which we draw. Now we return to Sita.

\section{The case of Sita}

In 2011 Sita returned to Hong Kong from Nepal to begin her secondary education, and her mother was convinced by Lagan to enroll her at MAT. Lagan was a Nepalese-community-based activist, who was also a liaison officer hired by MAT based on his network to assist in teacher and student recruitment at its recently formed English-based section. Though the school was a low prestige institution, known for poor academic results and serving a working-class student body, Sita found in it a good opportunity to bypass the Cantonese-based mode of instruction with which she had struggled in early primary education. The English-based section also put Sita into contact with a group of newly hired teachers from different ethnolinguistic backgrounds that connected her to a wider network of community workers and researchers.

Between the ages of 13 and 17, Sita made two return trips to Nepal that brought reunions with family and engendered feelings of connection to Nepal as her homeland. These feelings were heightened during the 2012-2013 academic year, when many students in the English-based section at MAT began to feel that 
the initial excitement of being enrolled in a public institution with, what was to them, unconventional pedagogical, linguistic, and social arrangements was not challenge-free. Although the school had locally advertised the new English-based section as driven by a tailor-made school curriculum focused on "critical thinking" and "problem-solving" approaches, and in line with a view of education as "more than passing exams", these pedagogical values later became a discursive space for social struggle, contestation and performance.

A critical event in the orientation of all school actors to this discursive space took place in October 2014 when Carlos and Lagan, two months after the school's English department head left due to conflicts with the administration, also parted ways with MAT after clashes over pedagogical agendas became irreconcilable (see Soto 2016 for further information). Both of them had been initially considered as key actors in getting the new English-based section at MAT running, yet eventually the school administrators judged Carlos and Lagan's non-textbook based educational philosophy as too lax and inadequate to prepare students for the public exams that students in Hong Kong sit at the end of secondary school. However, the two of them continued to work with some students from MAT through other institutions, including MCC, and assisted Sita in her application process to HKLC beginning in November 2014.

That same month, Sita and two classmates also involved in our research participated in a group interview conducted by Karen, Lisa and Steven, three undergraduate students at the Faculty of Education in The University of Hong Kong. The three university students were working on a course research assignment and focused their study on the Chinese language-learning experiences of students with ethnic minority backgrounds in the Hong Kong education system. Guided by their course tutor who at the time was Miguel's colleague, they approached Carlos and some of his former students (Sita, Pramiti and Radhika) in order to conduct a group interview with all of them.

The split from MAT opened a space for students in which to discuss the school's persistent use of group-based alignments and students' forms of dis-alignment from practices they found troubling. Extract 1 below shows how Sita and some of her classmates make sense of all of these issues, in part by highlighting perceived inequalities.

Extract 1. "So-called high class"

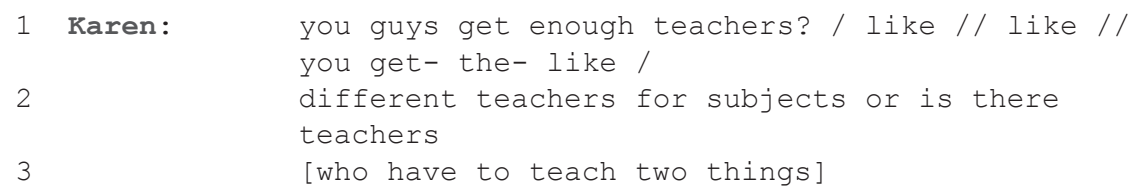




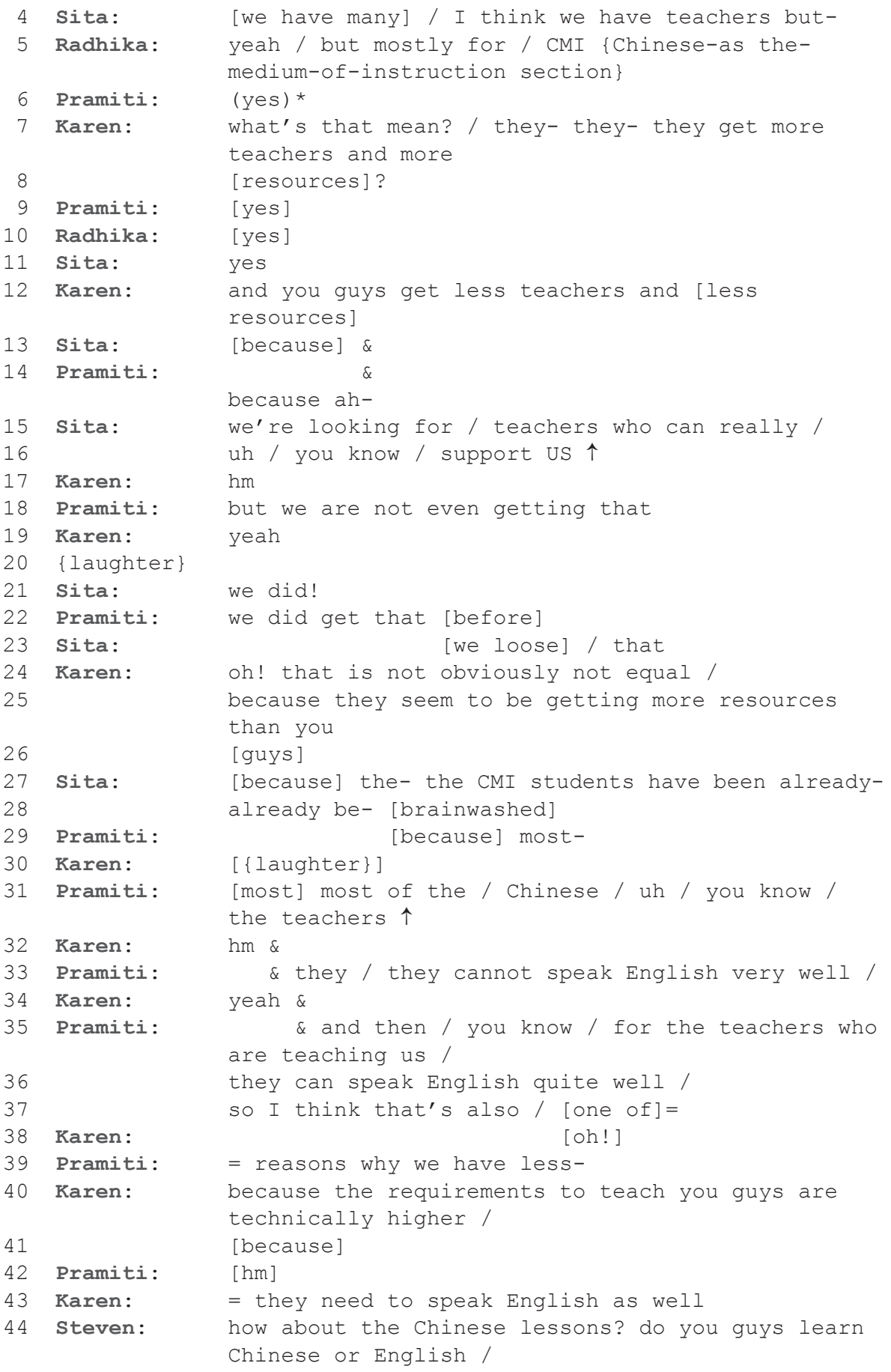


like / like you said you have a hard time understanding Chinese /

like listening to Chinese / do they explain / in / Chinese or do they explain in English? // [like for a certain word?]=

48 Sita: [uh]

\section{Steven:}

50 Radhika:

51 Steven:

52 Radhika:

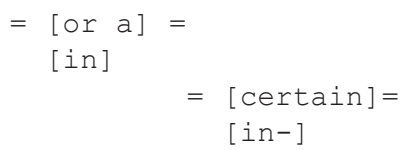

\section{Karen:}

72 Sita:

yes

but for the middle group and lower gro- group they explain us in English

yeah / [but even-]

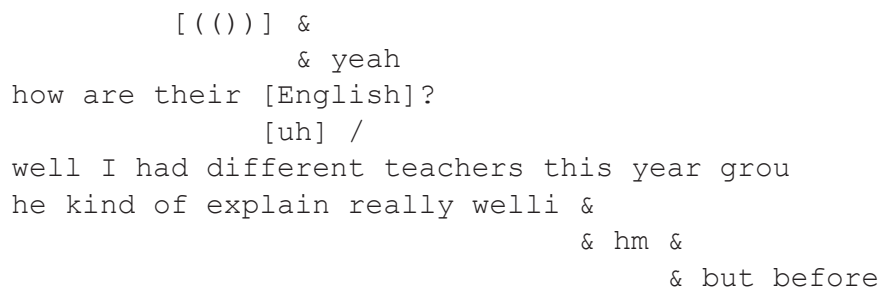

Karen:

75 Sita:

76 Karen:

\{laughter\}

80 Karen:

/ uh /

my teacher had a hard time to explain [in English ]

[ah! ] yeah / so I think(( )) like- because- some of the times / like / we- we wanna teach the language by completely speaking that language / like / for my French classes at school / they just keep talking to me in French

but I get the problem / the problem is that / if I don't understand something / and ask them / there is no point in them explaining it to me in French / 


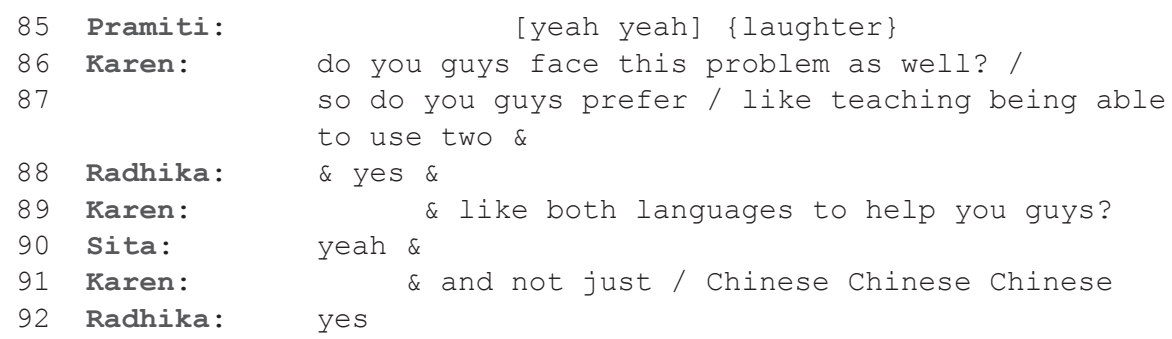

Extract 1 shows the extent to which pedagogy became a salient feature upon which interview participants negotiate social relations while at the same time layering official and unofficial voices/stances that depict MAT negatively. In so doing, they detach themselves from conventional associations established at the school between, on the one hand, teaching/learning styles involving language use and semiotic arrangements in the classroom (i.e. including the distribution of groupings of students within the space of the school as well as the linguistic labels typifying these groupings) and, on the other, the moral values and types of social persona associated with the categories of "good student" or "desirable ways of teaching and learning" upon which such teaching/learning styles and semiotic arrangements are legitimated. The forms of interpersonal alignment enacted to detach themselves from such emblematic associations are also discursively connected to the departure of Carlos and Lagan, after months in which they and the school administrators struggled over who gets to define what counts as proper ways of teaching and learning at the English-based section in MAT.

The interpersonal alignment emerges throughout two key segments in the extract, one regarded with the distribution of resources across the two sections at MAT (lines 1-43), and the other concerned with their teachers' linguistic accommodation in the teaching of Chinese as a subject in the English-based section (lines 44-92). In the first segment, Karen, Sita, Radikha and Pramiti coordinate their actions to achieve a common understanding regarding how the two sections in the school are related to one another. From issues concerned with unequal distribution of number of teachers across the two sections (1-11) to imbalance in the degree of support offered by their current teachers, in contrast to other types of teachers that they had in the past and lost (in what seems to be a reference to Carlos and Lagan's departure) (15-23), the accounts provided are collaboratively linked to inequity (24-26), leading to further contrasts that characterize students in the Chinese-based section as "brainwashed" (27-28) and students in the Englishbased section as requiring teachers with "higher" teaching qualifications (31-43).

The second segment of the extract brings about a crucial instance of reflexive reanalysis whereby official labels and associated types of personhood get 
collaboratively re-interpreted. In response to Steven's shift of topic towards the Chinese subject in the English-based section of the school (lines 44-53) Radhika explains that in her group the teacher of Chinese only uses Chinese in class, a claim that is reinforced by Sita and Pramiti via repetition and overlapping (lines 54-60). In her turn, Radhika refers to her group through the label of "high class" (line 54), a metasign which groups together a set of school-related labels upon which the social life of MAT is institutionally arranged (e.g., "advanced students" versus "low-achieving students" placed in "low groups"). That is to say, Radhika sets up a frame of interpretation in which Chinese classes in the English-based section are presented as arranged hierarchically according the students' proficiency, a common practice in many different subjects in public schools in Hong Kong where students are grouped according to their academic results.

However, after uttering the "high class" label, Radhika detaches personally from it by rephrasing it ("so-called high class") and accompanying it with the air-quote gesture, in what seems to signal a parodic take on the label itself, and, in turn, of the values and types of social persona associated with it (e.g., "good students"). This layering of an institutional frame with a parodic one through which the student signals shared ambivalent attitudes (i.e. official and interpersonal voices) is taken up by the rest of the interactants who orient towards Radhika's act by laughing out loud (line 55), followed by Sita's animation of Radhika's act of rephrasing in laughter (line 56).

From that point onwards, Karen offers a platform for building a joint stance together with the school students, and against their teachers of Chinese at MAT. Following up on Sita's response that her teachers in the middle and lower groups use English in the Chinese subject, which gets immediately framed (with the guide of Steven and Radhika) as one in which even in that case her teachers' lack of proficiency in English does not help her fully understand (lines 63-75), Karen recounts her own previous experiences as learner of French during her school days in the past. In so doing, she positions herself as a confused student who felt frustrated whenever her teachers attempted to explain, without rephrasing it in English, something that she did not understand well in French. This gives way to a series of exchanges with Radhika, Pramiti and Sita in which the students align with the interviewer through laughter (line 79), affirmative responses (lines 84, 85, $88,90,92$ ) or elaborations that highlight that their teachers do not support them or try to reach out for them, contrary to what the school students believe is their teachers' duty as educators.

The following subsections track down the process whereby such group-based alignments among the actors at this section of the school became persistent, therefore paving the way to alternative enregistered figures of identity. More specifically, 
they describe the process by which a specific set of multimodal signs were regrouped around new identity attributes that emerged in contrast to the values and types of social persona legitimated at MAT. In what follows we will first detail the irruption of such identity attributes in the life of Sita via examining the process by which she came into contact with HKLC, the international senior secondary educational institution that in 2015 would accept her on full scholarship. After that, the analysis will focus on the ways in which the new attributes were embodied in various activities and communicative styles within Sita's social network.

\section{Alternative institutions, new identity attributes}

Though Sita felt empowered within Carlos' pedagogical program and through activities organized by Lagan, she found herself otherwise struggling within an environment of instability at MAT. By the spring of 2013, the pair had turned Sita's attention towards HKLC as a site for greater academic and social attainment as Lagan had opened doors to collaborative activities with the school that he and Carlos considered as intellectually challenging for their students at MAT.

Simultaneously, Carlos and Lagan began preparing students who showed interest in applying for admission to HKLC, which follows the International Baccalaureate curriculum (also known as "IB curriculum") and, therefore, does not have to align with the official standards set up by the Hong Kong Education Bureau. According to its website, HKLC targets students aged 16 to 18 "who are already grounded in their own cultures but impressionable enough to learn from others", and has as its core values "international and intercultural understanding", "celebration of difference", "personal responsibility and integrity", "mutual responsibility and respect", "compassion and service", "respect for the environment", "a sense of idealism", "personal challenge", and "action and personal example".

Extract 2 is part of a research interview between Miguel and Sita that took place in the spring of 2013, after an absence of several months from MAT by Miguel. The excerpt shows how her feelings of connection to Nepal are articulated and negotiated at her own school past experiences at MAT and her future educational aspirations in HKLC. Forty minutes into the conversation with Sita, Miguel attempts to close the interview through providing a gloss about the purpose of the new round of interviews that he was conducting at the time with a group of students in Sita's class; he explains that, after one year since the last round, he intends to know more about old and new issues that each of the students was facing, and the interaction continues as follows: 
Extract 2. "We have to learn our own language"

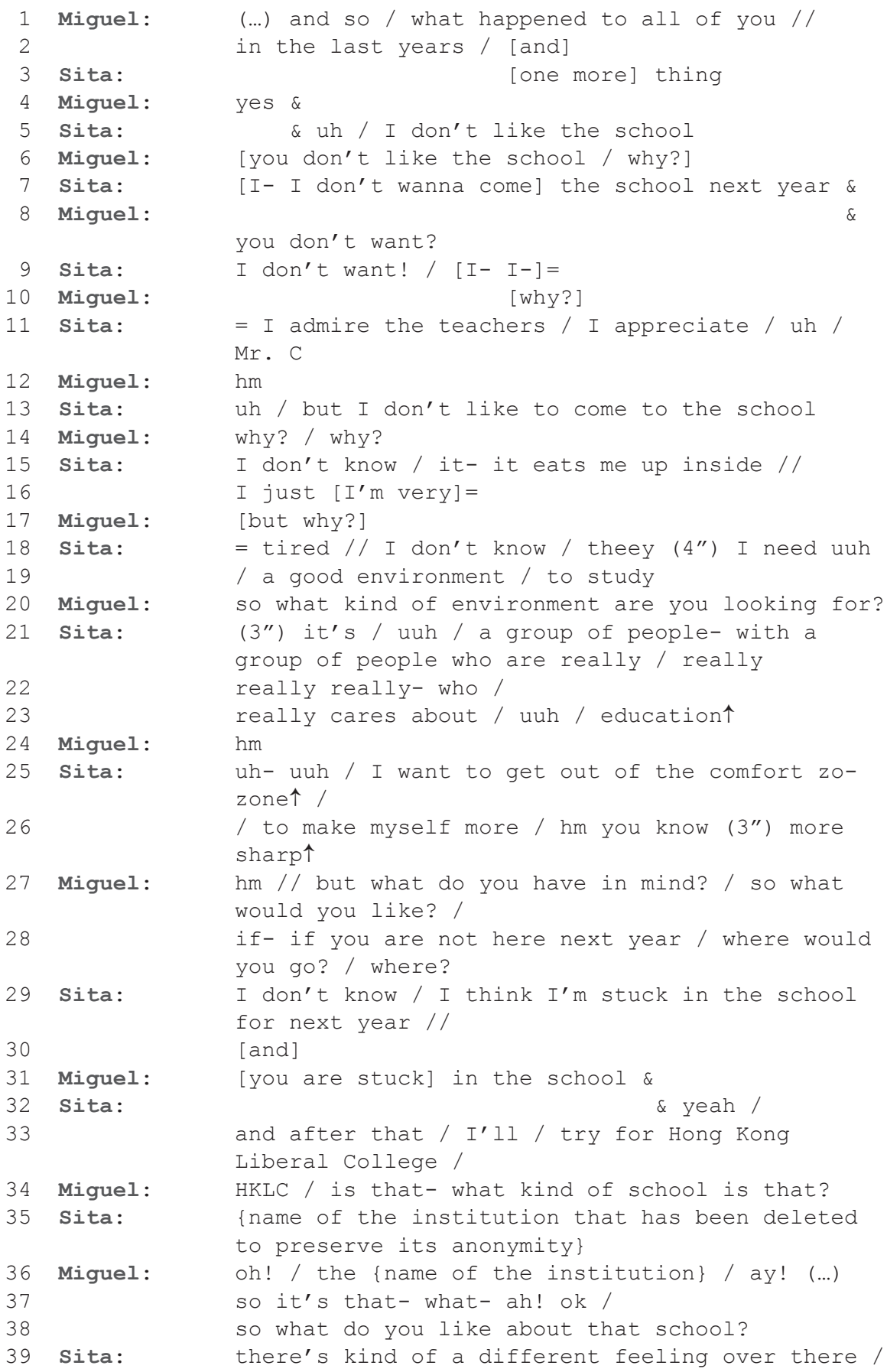




\section{Sita:}

\section{Miguel:}

Sita:

\section{Miguel:}

\section{Sita:}

\section{Miguel:}

Miguel:

\section{Sita:}

Miguel:

Sita:

Miguel:

\section{Sita:}

Miguel:

Sita:

\section{Miguel:}

Sita:

Sita:

Miguel:

Sita:

Miguel:

Sita:

Miguel:

\section{Sita:}

Miguel:

Sita: and there's people- there are a lot of people who are really uh /

really care about education $\uparrow$ /

but not only education / about the community $\uparrow$ /

about their own country^ //

but // but if- if we want to go to that school / we have to learn our own language

$\mathrm{hm}$

and that's the problem / I have to learn my own language first

so when you say my own language / uh (2")

so it sounds a little bit weird to me / because / I mean //

to me English is also one of you- your languages / right? //

[no!]

[and] / no?

I think English is not my own language / it's kind of / a part of / my life / but / it's not REAlly my- oh! I can(('t)) say my mother tongue /

[my mother tongue] =

[hm ]

$=\left(\right.$ is Nepali个) ${ }^{\circ} / /$

I see

(yeah) ${ }^{\circ}$

so but you need- you need to- to speak Nepali [if $]=$

[hm]

= you want to go to / that college?

$\left(2^{\prime \prime}\right) \quad$ [yeah ]

[alright] / I see

they- they- they need students who are kind of / uh /

whoo thinks about their own country and community who can make a change $\uparrow$ / this kind of stuff

but you feel- because you talk about your country //

so- but when you (())-

when you say your own country what country is that? (2") uh our motherland so which one is that?

Nepal

Nepal? / because you were born here yeaah [laugh]

[laugh] so to me it's a little bit / [difficult]=

[yeah but]

$=$ to understand

(2") Hong Kong yeah // Hong Kong too (2") 


\section{Sita:}

Miguel:

Sita:

Miguel:

\section{Sita:}

Miguel:

\section{Sita:}

Miguel:

\section{Sita:}

Miguel:

\section{Sita:}

Miguel:

maybe / if I go there (2") uuh // I may- I MAY make changes / in year 2 aha but there is a lot of things in Nepal that / uh / I don't know so then- so then what's- so interesting! / [then what's your] = [ $\{$ laugh $\}]$

= what's your country then? \{laugh because you say / ok / I was born here / [buut $]=$ [yeah \{laughing\}]

= I could make contributions here / but also to Nepal / but I don't know Nepal very well \&

Sita: \{nods her head yes\} 


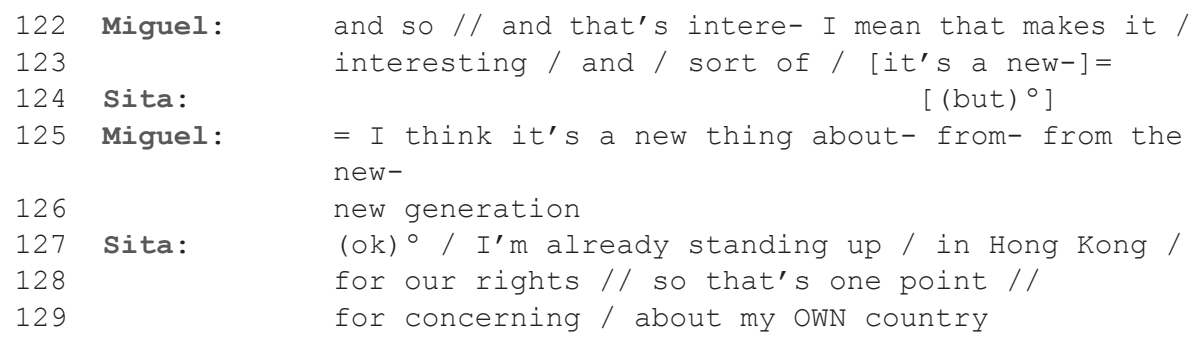

Miguel's research interview aimed at exploring Sita's daily routines, inside and outside the school to identify possible continuities and discontinuities with respect to his previously collected data. However, this research agenda does not seem to match Sita's concerns in the course of the conversation, and as Miguel's sequence of closing is developing in Extract 2, he is interrupted by the student who overlaps to introduce a new topic not explicitly addressed earlier in the interview: her discontentment with MAT and her personal aspiration to enroll in HKLC. This takes discursive work as Miguel and Sita negotiate meaning and stances on the type of social persona that HKLC is believed to be searching for.

The action begins with Sita shaping the course of the conversation through overlapping (line 3) with Miguel to foreground her dislike for MAT (line 5) and her desire to not re-enroll there the following academic year (line 7). She does so by highlighting her admiration and appreciation of the work done by her teachers in general, and by Carlos in particular (line 11), which allows her to detach from MAT as an educational institution without doing it from some of her closest interlocutors at it. Sita's introduction of this new topic seems successful; from then on, the interaction hinges around exchanges that orient to two main interactional segments related to the development of this topic: one in which Miguel and Sita try to find a common ground regarding the reasons why the latter does not want to come back to MAT (lines 14-26), and the other in which Sita's alignment with HKLC's ideas about language and territory are challenged and negotiated (lines 27-127).

In the first section, Sita and Miguel collaboratively establish a main contrast between MAT and HKLC. After two previous ineffective attempts (lines 6, 10), Miguel follows up on Sita's initial statements and asks about her reasons for not being at the school (line 14). This question, which is re-stated twice as Miguel tries to narrow down Sita's scope of answer, opens the door for Sita to position herself as a suffering individual who: (a) is being "eaten up inside" (line 15); and (b) needs a good environment to study (lines 18-19). This is then picked up by Miguel who requests from Sita a more explicit account of the type of environment that she would like to be in (line 20), which in turn allows Sita to align explicitly with what she characterizes as a social group of people that truly cares about education (lines 21-23). The link to such a group is indeed later re-framed as a condition for her to get out of her "comfort zone" and to be "sharper" (lines 25-26). 
In so doing, Sita relies on Miguel's questions in order to convey the implicit message that MAT does not care about education and does not offer the conditions for her to move beyond her comfort zone and get sharp. The contrast with HKLC is then made in the following exchanges. Asked about where she would go if she does not want to be at MAT (line 27-28), Sita acknowledges that she is stuck for the next year (line 29), followed by the indication that she will try for HKLC after (line 33). Miguel then asks about what makes her like HKLC (line 38), which leads to a more elaborated explanation in which Sita describes this institution as linked to a group of people who care about education, about the community, and about their own country and language (line 39-43).

The second section in the transcript involves more intensive negotiation of meaning and stance between Sita and Miguel. Once her lack of interest in MAT is made sense of, against the background of the educational/philosophical contrast that is established between MAT and HKLC, Miguel introduces two main topic shifts that make Sita's taken for granted ideas on language and territory accountable to closer scrutiny. These shifts are concerned with Sita's accounts of Nepali as her first language (lines 44-65), and of Nepal as her own country (lines 66-129). The interactional sequence in which language is the centre of attention to both interactants, is initiated by Sita who explains that if she and her classmates at MAT want to be accepted in HKLC they have to learn their own language. She goes on to account for this institutional requirement as a problem since, as she puts it, she has to learn her own language first (lines 44-47).

This is immediately challenged by Miguel who reacts by suggesting that English, the language of instruction at MAT that has also been part of Sita's linguistic repertoire since her early childhood, may also be considered one of her "first languages" (lines 48-50). In response to the challenge posed to the account that Sita has to learn her first language before she enrolls in HKLC, the student qualifies English as an important part of her life but not as her "mother tongue" (lines 53-58). This allows her to keep positioning herself as someone who has to get back to her family linguistic roots in order to stand a chance of accessing HKLC, a stance that is finally jointly ratified by her and Miguel (lines 59-65). At this point Sita continues expanding on HKLC's values by emphasizing that this institution is interested in students who are committed to their countries and communities and who want to make a change, which once again leads to a new sequence of action requiring Sita to provide further qualification of her statements - and of the involved alignments with HKLC (lines 69-81).

The new sequence is opened by Miguel who acts puzzled in trying to understand Sita's description of Nepal as her own country. He does so by drawing the student's attention to the fact that she was born in Hong Kong, which forces Sita to include this territory as one of her own countries ("Hong Kong too") (line 81). This 
is also followed by the acknowledgment that, if she is finally accepted to HKLC, she may make changes in the second year at this senior secondary institution (Form 6) (lines 81-83), which may be interpreted as making a change for Nepal, in connection to HKLC's value on taking on students who can make a change. As in the previous sequence, this re-orientation initially helps Sita to get Miguel's acceptance of the proposed frame of interpretation (line 84), though the latter's challenge is further taken up by Sita in the following turn, where she states that such changes can be difficult since she does not know much about Nepal (line 85).

Following up on Sita's concession, the two interactants re-orient themselves to the same topic by engaging in further exchanges in which Miguel recounts the contradictions he finds in Sita's affiliation to a given country, something that seems to be ratified by Sita in her final acknowledgement that "it is very confusing" (lines 85-98). This agreement may sit uncomfortably with Sita's alignment with a social persona that is attached to an imagined community of people who share the language and territory of Nepal - and in turn with the social persona that HKLC may be interested in. In this regard, Miguel's follow up may be interpreted as an attempt to reconcile the highlighted contradictions with reference to an alternative account in which Sita is positioned as part of a younger generation of transnationals who do not fit necessarily well in narratives based on fixed relationships between language and territory (lines 99-121).

Though this contribution is accepted by the student (line 121), the sequence finishes with Sita reframing her alignment with Nepal as her own country through linking it up with her commitment to standing up for the rights of the people who have Nepali background and live in Hong Kong - and probably in contrast with Miguel's example about his own son who might be seen as someone far from the type of social persona who struggles socioeconomically and who Sita wants to foreground (lines 124-129). Thus, this move allows her to reconcile the above-mentioned contradictions while at the same time keeping intact her stance as someone fitting in HKLC. In sum, the interactional negotiation of meaning and stance between Miguel and Sita makes particularly salient identity attributes around the experiences of struggling and fighting for the rights of an imagined community who share the language and the homeland of Nepal in Hong Kong.

These attributes became discursively linked to the label of "student activist" that Sita publicly attributed herself as a new emblem of identity (or social persona). Figure 1, a photo that she took and displayed on social media such as Facebook, is an example of the explicit use of this label for identity positioning, and of the linkage between the label and keywords associated with Carlos' pedagogical interests concerned with "critical pedagogy", "Hong Kong minority students", "Freire" (in reference to the Brazilian educator Paulo Freire, author of the book Pedagogy of the Oppressed and pioneer of critical pedagogy as a discipline), "change" or "dreams". 


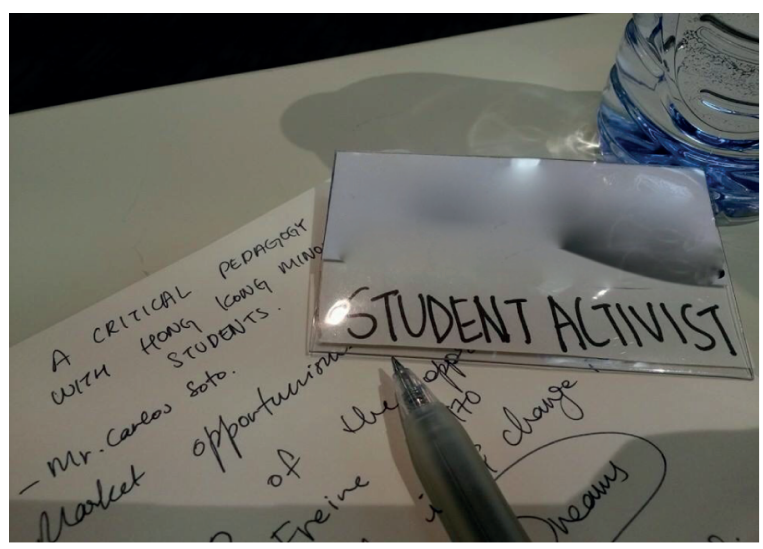

Figure 1. Student activist

The image shows a tag-name that Sita filled and notes she took at a Hong Kong international academic symposium on ethnic minority education in 2015 , three days after receiving her admission to HKLC. Sita and other members of our research program participated in a student panel at the conference while Carlos delivered a paper on his research as a critical educator in the Hong Kong local education system. But the attributes related to struggle and fight for the rights of the Nepali community in Hong Kong were not only emblematically related to explicit labels and keywords; these identity attributes were also embedded in various activities undertaken across different domains, genres and modalities. These will be analyzed below.

\section{Performing struggle and community activism}

In the course of Sita's trajectory, struggle and commitment to the Nepali community were also performed through a recurrent set of enregistered (linguistic and non-linguistic) signs that, in Sita's network, became "functionally reanalyzed as cultural models of action, as behaviors capable of indexing stereotypic characteristics of incumbents of particular interactional roles, and of relations among them" (Agha 2007:55). Such signs, or demeanor indexicals that concern "embodied indicators of status and character" (Goffman 1956), were built upon two main recurrent types of action in the course of her upward academic trajectory, from a low-prestige school to a highly reputed international educational institution in Hong Kong, namely: critiquing the Hong Kong public educational system; and engaging in Nepali community-based actions. 
In a 2-year period, from the moment in which the interview between Miguel and Sita took place in 2013 until Sita's acceptance to HKLC in 2015, these actions were mainly displayed in public spaces, mass media, online social media and academic forums. With regard to criticizing the Hong Kong public education system, this type of action tended to be enacted through activities concerned with: joining public gatherings to protest against educational policies on Chinese as a second language; participating at school fairs in which critical messages against government school policies on ethnic minority students were displayed; sharing with the Hong Kong and international media on personal conflicts and struggles, sending complaint letters on social justice to Hong Kong-based newspapers; joining Facebook group discussions with researchers, community workers, teachers and classmates about Hong Kong education policy; displaying personal artwork on Tumblr and Facebook; participating in academic conference presentations led by Carlos and attending other lectures at universities; and lecturing to tertiary audiences, including some of Miguel's classes on language, social class, ethnicity and equity at the Faculty of Education in The University of Hong Kong.

As for the Nepali community-based actions, these included activities around: performing traditional Nepali dance for the Hong Kong public, in collaboration with the Nepalese Association of Hong Kong; arranging fund-raising activities for Nepal's victims of earthquakes; participating in memorials to the Gurkha soldiers buried in Hong Kong as well as in monographs about their lives published on Hong Kong and Nepali-based media; and taking part in activities on online and media connected with the Nepalese Association of Hong Kong. A summary of all these actions and activities is shown in Table 1, with reference to predominant communicative genres and styles involved.

Table 1 helps identify patterns regarding the enregistered ways in which Sita's self-attributed identity of student activist was put into practice once HKLC became an objective for her and other actors in her social network. It also shows alignment with the core values displayed in HKLC's website that were described in the previous section. Nevertheless, an account of the patterned actions and communicative genres and styles that became emblematic of the social persona of a student-activist does not reveal the situated processes whereby actors' engagement with this type of discourse register is aimed to specific communicative purposes. An insight into these communicative purposes requires description of how such emblematic relationships get set up by Sita and other social actors in her network, in discursive contexts in which they negotiate alignments and de-alignments similar to those described in the Extracts 1 and 2.

We will show how this happened with reference to two examples, one concerned with a piece of written discourse (Extract 3) and the other with a Facebook 
Table 1. Actions, domains, genres and styles in the performing of student activism

\begin{tabular}{|c|c|c|c|}
\hline Types of actions & Social domains & Genres & Styles \\
\hline $\begin{array}{l}\text { - } \text { Critiquing } \\
\text { Hong Kong } \\
\text { local education } \\
\text { - Engaging } \\
\text { in Nepali } \\
\text { community- } \\
\text { based actions }\end{array}$ & $\begin{array}{l}\text { - Public Spaces } \\
\text { - } \text { Local English } \\
\text { and Chinese } \\
\text { language print, } \\
\text { television, and } \\
\text { radio mass } \\
\text { media } \\
\text { - Local Nepali } \\
\text { language media } \\
\text { - International } \\
\text { media } \\
\text { - Online social } \\
\text { media } \\
\text { - Academic } \\
\text { forums }\end{array}$ & $\begin{array}{l}\text { - Printed messages } \\
\text { (via posters, } \\
\text { iPads, t-shirts) } \\
\text { - Hand-made signs } \\
\text { - } \text { Letters to } \\
\text { newspaper editors } \\
\text { - } \text { Traditional } \\
\text { dance and song } \\
\text { performances } \\
\text { (for public fairs, } \\
\text { charitable events) } \\
\text { - Artwork } \\
\text { (drawing, ink, } \\
\text { watercolor) } \\
\text { - Academic } \\
\text { Power Point } \\
\text { presentation } \\
\text { - Public protest } \\
\text { - Facebook posts, } \\
\text { comments, } \\
\text { discussions }\end{array}$ & $\begin{array}{l}\text { - American standard variety, } \\
\text { in contrast to occasional } \\
\text { Indian English accents } \\
\text { when speaking with peers } \\
\text { in other genres } \\
\text { - Lexical choice of emotive } \\
\text { words (e.g., miserable, } \\
\text { exasperation, devastating), } \\
\text { educationally specialized } \\
\text { terms (e.g., transmission, } \\
\text { generative, transformative } \\
\text { pedagogy) and tier two } \\
\text { vocabulary in letters and } \\
\text { public addresses (e.g., } \\
\text { ambitions, aspirations, } \\
\text { psychologically, sectors, } \\
\text { reproduce) } \\
\text { - Collective reference to } \\
\text { Nepalese heritage (e.g., } \\
\text { our history, our ethics, our } \\
\text { ancestors) } \\
\text { - Anecdotes of personal } \\
\text { struggle } \\
\text { - Comic/graphic illustrations } \\
\text { with captions to complain } \\
\text { - Impassioned ad lib speech } \\
\text { with faster, louder pace; } \\
\text { prepared speeches in } \\
\text { slower, more deliberate } \\
\text { pace emphasizing selected } \\
\text { words by lengthening and } \\
\text { increasing their volume }\end{array}$ \\
\hline
\end{tabular}

post (Figure 2). Extract 3 is part of a testimony that Sita submitted to MCC, an institution that collaborated with Lagan and members of other Nepalese community organizations through Parmila, a female staff at MCC who has Nepalese background. Asked by Parmila to provide a testimony that the social center could file as evidence of its impact, for accountability and funding purposes, Sita submitted a letter in December 2015, a few months into her first term at HKLC, that provides a personal rationale for all of the actions, signs, actors and core educational values shown in Table 1. 


\section{Extract 3. Written testimony submitted to Methodist Community Center}

I first join the centre in 2013 as far as I can remember. I joined it when my friends in high school and I was in grade 8, and they asked me whether I would want to join a dance group with them. We named "C Girls" for our dance group and this name was originated from our group for the girls team when we went for our first camp back in high school. "C" means courage, collaboration, courtesy, communication, and capital. These terms were important for us for our team to empower ourselves as a young women in the Nepalese community, through our cultural dance. Dancing was more than just an entertainment for us, well at least it was for me. "C Girls" was sponsored by Methodist Community Center in 2013 and we did a lot of cultural performances in different places and in many events. We would always make our time to rehearse and through this we learned to collaborate and to communicate which built our social capital and enhance our learning. These were the significant factors that helped us to grow our sense of our culture and our identities.

Through this centre, we did other activities such as workshops on about Gurkha, Research led by Carlos Soto, volunteering in workshops and other activities [...] which all were intriguing to me because I had never had this space in my previous school or anywhere to begin with, and this has helped me to explore more on about my culture identity and my abilities to do something in the community. I began to be more aware about issues in my own community because all my friends (including Parmila and other teachers who were involved) came together and worked together in order to empower ourselves and to be an author of our own lives, which was by organising an event with help of my dear friends, leading the programs, presenting in universities and choreographing our dance and having a communication through social media. I never had this privilege to do so many things in my previous school and I never knew that I could do so many things in the community and outside the community. I have learned to value myself, where I come from and where my origins are from, and who I really am.

Despite all the traumatic experiences that I have been through in my personal life, this organisation was like a shelter to me where I could do things that I enjoy and my experience in this organisation has overcome my fear of being a women. Women who are represented as an emotional, delicate and powerless species in a community. I am no longer the same girl as I was before [...] I have learned to empower myself and I have learned the importance of do something for my community and my role, not as a women's role that the society expects or define but I have become an author of my own life and that my role, my existence and my contribution in the community is important for my people, now and in the future [...]

The text continues for an additional two paragraphs in which Sita appreciates the contributions of Lagan in building her courage and widening her social circle, Carlos and Miguel for enhancing her learning and critical thinking, Manju for leading her dance group, and Parmila for being "a role model for all of us [who] has been empowering the Nepalese community" despite her weakened position due to 
patriarchal power structures. She closes with an affirmation of her commitment to "kindness, love support," and "having empathy and understanding different cultures" as a human value.

In the text, she accounts for most of the actions summarized in Table 1 as connected to a journey of empowerment and growing sense of cultural identity that: (a) begun in 2013; (b) evolved in collaboration with her social network of classmates (e.g., Manju and the other members of the C-Girls group), teachers (e.g., Lagan and Carlos), community workers (e.g., Parmila) and researchers (e.g., Miguel); (c) took her away from "traumatic experiences" in her personal life and from her previous school ("I had never had this space in my previous school"); and (d) is anchored in core human values concerned with understanding an accepting "different cultures".

In particular, Sita's account of actions and actors position her as a young woman who empowers herself to work for the present and future of the Nepalese community in Hong Kong, which she explicitly considers her own community. In so doing, she foregrounds her alignment with Parmila who is explicitly portrayed in the letter as a role model in empowering the community though her role at MCC (and not directly linked to the Nepalese Association of Hong Kong which is mainly headed by male representatives). That is to say, Sita offers the requested evidence by MCC through performing a social persona that fulfills the purposes of a social institution preoccupied with empowerment while at the same time aligning with Parmila as a key community actor.

With regard to the example of a Facebook post, Figure 2 shows a work-inprogress piece of artwork that Sita shared on February 2015, after initiating her application to HKLC's scholarship program.

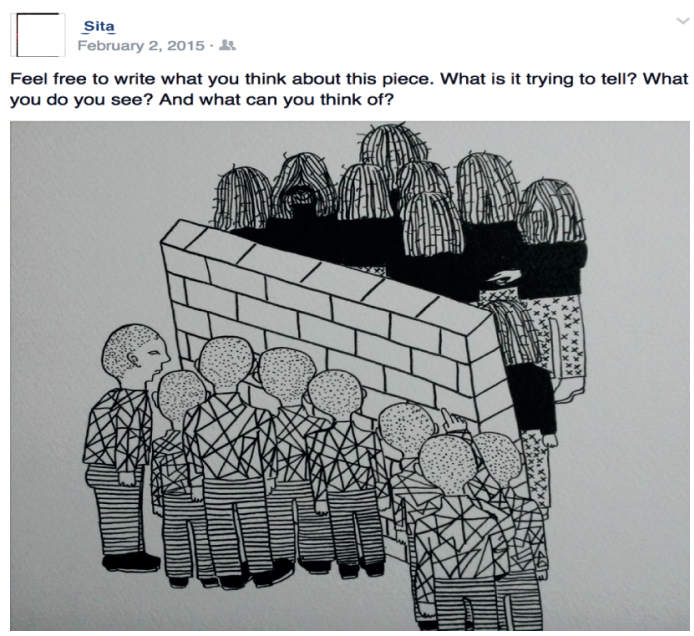

Figure 2. Artwork on Facebook 
The image depicts two groups separated by a brick wall, each in respective uniforms. Besides their uniforms, the two gender-ambiguous groups can be distinguished by their hair styles; the figures in the foreground with shaved heads and the figures opposite the wall with long hair that obscures their faces. Along with the image, Sita posted an invitation for feedback, making these posts spaces for identity performance and interaction with interlocutors in her network. Table 2 contains the Facebook dialogue that followed the posting of the image in Figure 2.

Table 2. "The mustache is just a little symbol"

\begin{tabular}{|c|c|c|}
\hline Date/Time & Name & Message \\
\hline February 2 , at $19: 42$ & Carlos & I love it. Wow. No sarcasm. \\
\hline February 2 , at $19: 44$ & Carlos & You need to do an exhibition this summer. \\
\hline February 2 , at $19: 47$ & Sita & Carlos Enrique Soto, Thanks $;$ \\
\hline February 2 , at $20: 03$ & Carlos & $\begin{array}{l}\text { This is a deceptively simple drawing that deals with themes } \\
\text { of separation, isolation, identity, and social grouping. I see } \\
\text { two groups separated by a wall, but beyond that, the meaning } \\
\text { is ambiguous and open to interpretation. On first sight, one } \\
\text { might assume that one group is male and the other is female, } \\
\text { but this doesn't have to be true. It's unclear how the groups } \\
\text { and individuals feel about the wall, our if they even know } \\
\text { what's on the other side. Did they build the wall themselves? } \\
\text { There's an individual on each side gesturing our pointing } \\
\text { towards the wall. Is anyone listening to them? There's only } \\
\text { one face visible, but that face seems unconcerned with the } \\
\text { scene. }\end{array}$ \\
\hline
\end{tabular}

February 2, at 00:35 Carlos The groups are uniformed, and have been made distinct effectively through the use of intersecting lines, parallel lines, crosses, and dots. While the figures in the foreground evoke concentration camp prisoners, the long-haired figures seem faceless and monster-like, though not threatening. There's no background scenery, just two groups, a wall, and maybe a conflict. It's definitely a piece that makes me curious about the world in which the scene is set, and makes me question our own world. It's a departure from your earlier pieces which explicitly deal with internal struggle.

February 2, at 08:31 Pramiti wonder why the mens are bold. \& the hair looks a bit weird. I somehow see a person with a mustache too.

February 2, at 08:32 Pramiti They seem to be pointing at each other

February 2, at 08:33 Linda I think it shows how media tries to differentiate between male and female when in fact,we're not quite so different after all.

February 2, at 08:34 Linda But it's a lovely drawing nonetheless $\odot$

February 2, at 08:35 Sita Thank you, Linda $\odot$ 
Table 2. (continued)

\begin{tabular}{|c|c|c|}
\hline Date/Time & Name & Message \\
\hline February 2 , at $12: 35$ & Sita & $\begin{array}{l}\text { Pramiti, I drew the mustache to let people know that group } \\
\text { aren't females. I thought people might think that the group } \\
\text { with long hair might be mistaken for women. The mustache } \\
\text { is just a little symbol to define that these creatures have no } \\
\text { specific gender. }\end{array}$ \\
\hline
\end{tabular}

February 2, at 12:39 Sita Carlos \& Pramiti, have a surveillance to the wall I drew and the open the space. Does it say anything to you, does it remind you of something? The negative space has its meaning and the pointed fingers has its meaning.

February 3, at 16:52 Aaron Anti-Gay!!

February 3, at 16:54 Aaron or,..may be two different group; Skin Head Gangs vs American Bad Boys. Respect territories!!

February 3, at 17:57 Sita Aaron, well the thing is that I ain't anti-gay but what makes you think that it's anti-gay?

February 3, at 19:52 Carlos Sita, I think the gender is ambiguous enough without the mustache. The mustache is not necessary. You are using the word "surveillance" incorrectly again. Pramiti and I noticed it observed the wall. I think the open space is there for irony. Figures on each side are pointing at the wall, and ask the figures seem fixated on it, yet no one send aware of all the open space. In other words, no one is aware that they can simply walk around the wall, that the wall doesn't have to be a border or a maker of segregation or territory.

Sita's artwork became in her network an emblem of the attributes of a student activist who is concerned with struggle, communities/social groups, and empowerment. In the interaction above, this metapragmatic model of Sita's identity emerges from her interactional efforts to engage others (particularly Carlos and Pramiti) in the interpretation of a semiotic repertoire that is collaboratively constructed by all participants as indexing a critical stance towards the social world. Following the heading that accompanies the image posted by Sita ("feel free to write what you think about this piece. What is it trying to tell? What do you see? And what can you think of?"), and after an initial exchange in which Carlos and Sita engage in an act of appraisal, Carlos provides two further analytical contributions focused on her choices in repertoire.

In the first of these (February 2, at 20:03), he foregrounds general characteristics of the drawing such as the key themes ("separation", "isolation", "identity", and "social grouping"), the ambiguous management of gender ("one might assume that one group is male and the other is female, but this doesn't have to be true"), or the relationship between the two portrayed groups and between these and the 
wall ("how the groups and individuals feel about the wall"). Though in the end of this contribution Carlos also refers to choices made by Sita regarding gesturing and facial expression in the drawing, this analytical dimension is further exploited in the following message (February 2, at 00:35), where he highlights more specific semiotic decisions concerned with the management of uniformization and distinction through intersecting lines, parallel lines, crosses, dots, body characterization (i.e. hair) and background in the piece of drawing.

To Carlos, these choices evoke characteristics that apply differently to the figures grouped across the two sides of the wall, and this is taken up as indexing a critical attitude towards the social world that goes beyond Sita's previous focus on internal struggle. This exchange in the late evening gives way, in the following morning, to two pairs of new contributions by Nepali peers who seem to take Carlos' initial interpretation that one group in the drawing is male and the other is female, accompanied by specific comments on stylistic choices such as the use of mustaches (February 2, at 08:31) or the portrayal of specific gestures (February 2, at 08:32). Sita's attempts to drive her interlocutors' attention to her repertoire continue further, though. After having thanked Linda, a senior student from another Hong Kong school that serves ethnic minority students (February 2, at $08: 35$ ), Sita contributes again four hours later to qualify Pramiti's point on the mustache by describing it as a "little symbol" deliberately ascribed to the group with the long-hair to neutralize possible gender-based interpretations (February 2, at 12:35), followed by a new message in which she calls Carlos' and Pramiti's attention to the wall and the use of pointing fingers (February 2, at 12:39), in an attempt to elicit more interpretations.

The value of Sita's artwork as an emblem of the attributes of a student activist also emerges in the form of an interactional alignment between Sita and Carlos, following the contributions by Aaron, a young adult Nepali male in Hong Kong who associates Sita's piece with anti-gay sentiments (February 3, at 16:52) and gangs confrontation on territory (February 3, at 16:54). After Sita rejects the anti-gay interpretation, Carlos replies to the previous contributions that Sita had previously addressed both to him and to Pramiti, and elaborates on the wall and the open space next to it, in the piece of drawing under scrutiny, leading to a more detailed account of the ironical layer that Sita might have wanted to communicate in her piece of artwork, which in turn seems to refute Aaron's focus on territory ("no one is aware that they can simply walk around the wall, that the wall doesn't have to be a border or a maker of segregation or territory").

A few weeks later, Sita re-stated her critical stance in regards to struggle and social groups by posting this piece of art online, with text taken from a portfolio meant for HKLC underneath the drawing, and with the addition of hashtags for online categorization of the post: 
I illustrated this piece to represent people from opposing parties. This is a mindset that most human have, the idea of scapegoating the obstacles that interrupts our path. It is not the obstacles that we're suppose to scapegoat, it's us. The problem is our attitude and our mindset. In the illustration, the group of people with no hair represents freedom while the other group with hair represents misery in their lives. It tries to show that the opposing parties are only blaming the wall, instead of helping one another.

Theme: Diversity, Exclusion and segregation.

Title: Untitled Media: Ink on paper Size: $8.5^{\prime \prime}$ by 11" (estimated)

Date:2nd February, 2015

\#my art \#personal arts \#artist on tumblr \#ink on paper \#ink black \#scale young artists \#female artists \#society \#tumblr art \#2015 0202 \#diversity \#segregation \#exclusion studies

That re-post of her art is not just another instantiation of a recurrent individual social persona. It also displays Sita's experiential, intellectual, emotional, and social participation in an online Facebook community "whose orientation is not towards the nation-state but towards ideals and imageries drawn from the wider world, and involving specific spaces of deployment, specific actors and specific codes of meaningful practice", a "light" community at once "local" but also "translocally infused and framed" (Blommaert 2016: 68). The flexible and fast-moving structure available there facilitates Sita's flipping of normative, slow-moving frameworks like those of MAT focused on "reciting", resulting in a pivot from the first dialogically oriented post of her art to the more expository style of the second post that prods for those in her network to take up the themes she finds central to her experience. We will respond in due time to this prodding, along with what these data tell us about communities, and hopefully in a way to allows us to get beyond convention, as Sita has reminded us to do through the symbolism of the wall in her illustration. We turn now to the final discussion in this article, in an attempt to feedback to ongoing debates on reflexivity, language and late modernity.

\section{Reflexivity, language and youth in late modern Hong Kong}

Sita's case reveals the importance of looking into the networked dynamics underpinning what often looks just as "personal powers" (Archer 2007). In this article, we have departed away from sociological accounts of reflexivity based on isolated interviews conducted with individuals, towards examination of networked dynamics through the lens of linguistic ethnography, with the aim of tracking down the cultural formation of discourse register. Such an account has indeed allowed us to frame Sita's multimodal acts of communication as instances of identity 
performance that are enacted by her in contexts where she collaboratively constructs alignments with other social actors.

These alignments that emerge from our data are far from being constituted as local instances of spectacular action, though. Instead, they emerge in response to a series of socio-institutional events that involve an intricate web of actors and institutions operating on different discursive fields - each of these fields bringing different "centres of authority" (Blommaert 2010) over clusters of semiotic features (i.e. thematic domains, places, roles, identities and relationships), all of it within the logic of an increasingly stratified educational system that seems to be particularly reinforced by institutional policies of economic neoliberalism marshalling the state's support to the detriment of social protection and public interest regulations (Harvey 2005).

In the context of the Hong Kong public educational system, the insufficient support and policies shifted toward marketization has pushed schools to compete with each other over scarce resources, within an institutional logic that ranks and categorizes schools according to their students' results in the university entrance examinations (Leung 2013). Under these circumstances, low prestige institutions such as MAT struggle to maintain a minimum intake, which led MAT to capitalize on students with working class ethnic minority backgrounds to boost its enrolments. At the outset, this strategy worked well for parties involved. On the one hand, MAT survived as an institution, therefore ensuring mid-term stability to administrators, teachers, students and parents. On the other, students like Sita who had previously struggled with the Cantonese gained access to a newly set up English-medium section and new teachers from different ethnolinguistic backgrounds that connected the students to a wider network of community workers and researchers.

However, the lack of a comprehensive adjustment of the school to the new division resulted in unexpected tensions among teachers and students across the Chinese-based and the English-based sections of the school, over who got to define what counts as proper ways of teaching and learning. As Hong Kong public schools such as MAT follow the official curriculum and standards set up by the government, the normative expectation at them privileges alignments with the traditional language and culture of the territory of Hong Kong. These tensions were played out in the discursive terrain of pedagogy against which social actors were morally categorized (i.e. "good" and "bad" teachers, students and teaching/ learning styles) according to choices over language and discourse register (i.e. commitment to Cantonese, even in the English-based section of the school, as well as to traditional teaching/learning styles). In contrast to MAT, private institutions such as HKLC bypass the government's pedagogical patterns of normativity. 
As postcolonial Hong Kong is officially positioned as "Asia's world city" (Kennedy 2012), the city has become a global financial and economic hub, this new role followed by public and private policies oriented to attract human and material resources from all over the world, and accompanied by new official discourses representing diversity as a key cultural feature (Flowerdew 2004). Thus, expensive international schools originally founded to cater for the educational needs of the children of the colonial elites adjust now to the new expatriate and Chinese elites by bringing the discourses and values of the IB curriculum which foreground an internationalist ethos that makes important room for alignments with languages and cultures associated with other territories.

It is precisely at this point that reflexivity comes more explicitly into the picture, though not necessarily in the way as it does in Archer's account. Sita and her peers at MAT began to engage in situated mocking interactional practices by reflexively re-appropriating their school's normative patterns and related social/ discursive forms of organization, and by putting an alternative order in place (i.e. teachers and students in the Chinese-based section as "bad" in contrast to teachers and students in the English-based section). However, their lack of engagement with the school's legitimated values ended up jeopardizing their chances of succeeding in the Hong Kong public educational system.

In fact, the school administrators and relevant actors in the Chinese-based section were key centres of authority with a privileged position to define the conventions that all teachers and students in the school are expected to comply with, which ultimately led to the departure of the teachers in the English-based section of the school who encouraged Sita and her peers to take a critical stance (i.e. Carlos and Lagan). Following these events, Carlos, Lagan and other actors such as Parmila attempted to direct Sita (and other students in Sita's network) towards re-grouping a set of semiotic signs as part of Sita's repertoire in becoming recognized by HKLC as a legitimate candidate for admission.

As described elsewhere in relation to neoliberal tertiary institutions in the US (Urciuoli 2003), HKLC created its own discursive field by relying on a set of "mission" values that, although denotatively empty, draw their force from the indexical roles which they play in articulating marketing devices linked to the cultural communities of the business and management world. Thus, the ethnographic analysis of the discursive emergence of networked reflexive acts pinpoints the very situated mechanisms of socialization by which individuals gain cultural capital (Bourdieu 1986) through coordinated orientation towards those values - even if this coordination does not involve families as in contrast to traditional societies. This capital, which in Sita's case is constituted through the cultural formation of a discourse register of activism, allowed her to scale up the stratified educational 
system of Hong Kong - under the support of other institutions such as MCC which are also part of a neoliberal, institutional logic via providing support for marginalized communities outside of the structures of the nation state.

Recognition of the capital that Sita and other youngsters built, in part through participation in our research and the network in which it was situated, brings us back full circle. Though we began this article with a shift from researcher to participant reflexivity, ultimately, the case of Sita points us back to our work as language-based researchers and educators working from distinct traditions. This study compels us to consider how we use a critical sociolinguistic approach, which challenges the taken- for-granted in relation to youth trajectories through descriptive linguistic ethnography, to inform a critical pedagogical approach, which applies the insights from linguistic ethnography to transformational educational and linguistic projects. Moreover, we have displayed how language learning, with specific attention to register, can be reflexively used by students, educators, and researchers to shape, over time, trajectories of identification and involvement of social movements.

Furthering this work, though, requires a fuller, clearer picture of social life than that which we offered here through a study of Sita's trajectory of identification. Indeed, the (online and offline) contemporary communities Sita inhabited and used for discursive and reflexive work can be seen as arising from historical shifts that alter the contemporary nature of diaspora and integration into social life (Blommaert 2016b). We hope to contribute to a re-imagining of identity and social action under current conditions of what has been termed as "superdiversity" (Blommaert 2013) by heeding the call for research that goes beyond traditional notions of diversity and categories of identity such as ethnicity (Maly \& Varis 2015). We will do this in future work by returning not just to Sita, but to the whole group of her friends and peers who joined our youth research program which asked them, and us, to consider what "community" meant vis-a-vis official discourses on community we all encountered in Hong Kong.

\section{Acknowledgements}

We want to thank Adam Jaworski, Ben Rampton and Jan Blommaert for their useful comments to earlier versions of this article. Needless to say, misapprehensions are ours. This work was supported by the University of Hong Kong's Seed Funding Programme for Basic Research. 


\section{References}

Agha, A. 2005. Voice, footing, enregisterment. Journal of Linguistic Anthropology 15 (1): 38-59. doi: 10.1525/jlin.2005.15.1.38

Agha, A. 2007. Language and Social Relations. Cambridge: CUP.

Appadurai, A. 1990. Disjuncture and difference in the global cultural economy. Theory, Culture and Society 7 (2): 295-310. doi: 10.1177/026327690007002017

Archer, M. S. 2007. Making our Way through the World: Human Reflexivity and Social Mobility. Cambridge: CUP. doi:10.1017/CBO9780511618932

Archer, M. S. 2010. Routine, reflexivity, and realism. Sociological Theory 28 (3): 272-303. doi:10.1111/j.1467-9558.2010.01375.x

Archer, M.S. 2012. The Reflexive Imperative in Late Modernity. Cambridge: CUP. doi: $10.1017 / C B O 9781139108058$

Austin, J. 1962. How to do Things with Words. Oxford: OUP.

Bakhtin, M. 1986. Speech Genres and Other Late Essays. Austin TX: University of Texas Press. Bauman, Z. 1998. Globalization: The Human Consequences. New York NY: Columbia University Press.

Beck, U. 1992. Risk Society: Towards a New Modernity. London: Sage.

Blommaert, J. 2010. The Sociolinguistics of Globalization. Cambridge: CUP. doi:10.1017/CBO9780511845307

Blommaert, J. 2013. Ethnography, Superdiversity and Linguistic Landscapes. Chronicles of Complexity. Bristol: Multilingual Matters.

Blommaert, J. 2016. Commentary: Indonesia, its youth and 'light communities' [Tilburg Working Papers in Culture Studies, Paper 162]. <https://www.tilburguniversity.edu>

Blommaert, J. 2016b. New forms of diaspora, new forms of integration [Tilburg Papers in Culture Studies, Paper 160]. <https://www.tilburguniversity.edu>

Bourdieu, P. 1986. The forms of capital. In Handbook of Theory and Research for the Sociology of Education, J. Richardson (ed.), 241-258. NewYork NY: Greenwood.

Bourdieu, P. \& Wacquant, L. J. 1992. An Invitation to Reflexive Sociology. Chicago IL: University of Chicago Press.

Caetano, A. 2014. Defining personal reflexivity: A critical reading of Archer's approach. European Journal of Social Theory 18 (1): 1-16.

Copland, F. \& Creese, A. 2015. Linguistic Ethnography. Collecting, Analysing and Presenting Data. London: Sage.

Creese, A. 2008. Linguistic ethnography. In Encyclopedia of Language and Education, Vol. 10: Research Methods in Language and Education, 2nd edn, K. A. King \& N. H. Hornberger (eds), 229-241. Dordrecht: Springer. doi:10.1007/978-0-387-30424-3_257

Duchêne, A., Moyer, M. \& Roberts, C. 2013. Language, Migration and Social Inequalities: A Critical Sociolinguistic Perspective on Institutions and Work. London: Multilingual Matters.

Erni, J. N. \& Leung, L. Y. M. 2014. Understanding South Asian Minorities in Hong Kong, Vol. 1. Hong Kong: Hong Kong University Press. doi:10.5790/hongkong/9789888208340.001.0001

Fleming, K. 2015. Ideology, Identity and Linguistic Repertoires among South Asian Students in Hong Kong. PhD dissertation, The University of Hong Kong. <http://hdl.handle. net/10722/222399> doi:10.5353/th_b5689270

Flowerdew, J. 2004. The discursive construction of a world-class city. Discourse \& Society 15 (5): 579-605. doi: 10.1177/0957926504045033 
Giddens, A. 1991. Modernity and Self-Identity: Self and Society in the Late Modern Age. Cambridge: Polity Press.

Goffman, E. 1956. Stigma. Notes on the Management of Spoiled Identity. New York NY: Touchstone.

Goffman, E. 1981. Forms of Talk. Philadelphia PA: University of Pennsylvania Press.

Gumperz, J. 1982. Discourse Strategies. Cambridge: CUP. doi:10.1017/CBO9780511611834

Heller, M. 2002. Éléments d'une sociolinguistique critique. Paris: Hatier.

Heller, M. 2007. Distributed knowledge, distributed power: A sociolinguistics of structuration. Text \& Talk 27 (5-6): 633-653. doi:10.1515/TEXT.2007.029

Hymes, D. 1974. Foundations in Sociolinguistics: An Ethnographic Approach. Pennsylvania PA: University of Pennsylvania Press.

Kennedy, K. J. 2012. Immigration and Hong Kong: 'New Immigrants' and Ethnic Minorities. UNESCO-KEDI Regional Policy Seminar - Education Policy: Making in the Age of Migration in Asia and the Pacific, July.

Kubota, R. 2014. The Multi/Plural turn, postcolonial theory, and neoliberal multiculturalism: Complicities and implications for applied linguistics. Applied Linguistics, 1-22. doi: 10.1093/applin/amuo45

Leung, Y. Y. M. 2013. Education Reform in Hong Kong: Power-status, School Strategy and Social Inequality. PhD dissertation, The University of Hong Kong. <http://hdl.handle. net/1783.1/62278>

Lucy, J. A. 1993. Reflexive Language. Reported Speech and Metapragmatics. Cambridge: CUP. doi: 10.1017/CBO9780511621031

Martín-Rojo, L. 2010. Constructing Inequality in Multilingual Classrooms. Berlin: Mouton. doi:10.1515/9783110226645

Maly, I. \& Varis, P. 2015. The 21st-century hipster: On micro-populations in times of superdiversity. European Journal of Cultural Studies, 1-17. doi:10.1177/1367549415597920

May, S. (ed.). 2014. The Multilingual Turn: Implications for SLA, TESOL and Bilingual Education. New York NY: Routledge.

Pérez-Milans, M. 2015. Language education policy in late modernity: Linguistic ethnographies in the European Union. Language Policy 14 (2): 99-108.

doi:10.1007/s10993-014-9354-7

Pérez-Milans, M. 2016. Language and identity in linguistic ethnography. In The Routledge Handbook of Language and Identity, S. Preece (ed.), 83-97. Abingdon: Routledge.

Pérez-Milans, M. \& Soto, C. 2014. Everyday practices, everyday pedagogies: A dialogue on critical transformations in a multilingual Hong Kong school. In Reflexivity in Language and Intercultural Education: Rethinking Multilingualism and Interculturality, J. Byrd Clark \& F. Dervin (eds), 213-233. New York NY: Routledge.

Rampton, B. 1995. Crossing Language and Ethnicity among Adolescents. London: Longman.

Rampton, B., Tusting, K., Maybin, J., Barwell, R., Creese, A. \& Lytra, V. 2004. UK linguistic ethnography: A discussion paper. <www.Ling-ethnog.org.uk>

Sacks, H., Schegloff, E. A. \& Jefferson, G. 1974. A simplest systematics for the organization of turn-taking for conversation. Language 50: 696-735. doi:10.1353/lan.1974.0010

Silverstein, M. 1976. Shifters, linguistic categories, and cultural description. In Meaning and Anthropology, Keith H. Basso \& Henry A. Selby (eds). New York NY: Harper \& Row.

Silverstein, M. 2005. Axes of evals: Token versus type interdiscursivity. Journal of Linguistic Anthropology 15 (1): 6-22. doi:10.1525/jlin.2005.15.1.6 
Soto, C. 2016. Empowering Low-income Ethnic Minority Students in Hong Kong through Critical Pedagogy: Limits and Possibilities in Theory and Practice. PhD dissertation, The University of Hong Kong. <http://hdl.handle.net/10722/223611>

Tusting, K. \& Maybin, J. 2007. Linguistic ethnography and interdisciplinarity: Opening the discussion. Journal of Sociolinguistics 11 (5): 575-583. doi:10.1111/j.1467-9841.2007.00340.x Urciuoli, B. 2003. Excellence, leadership, skills, diversity: Marketing liberal arts education. Language \& Communication 23: 385-408. doi:10.1016/So271-5309(03)00014-4

Wortham, S. E. 2005. Socialization beyond the speech event. Journal of Linguistic Anthropology 15 (1): 95-112. doi:10.1525/jlin.2005.15.1.95

Wortham, S. 2006. Learning Identity: The Joint Emergence of Social Identification and Academic Learning. Cambridge: CUP.

\section{Appendix. Symbols used in the transcripts}

$\begin{array}{ll}\text { Laura: } & \text { participant } \\ \text { CR } & \text { (Capital letters) loud talking } \\ \text { ee } & \text { vowel lengthening } \\ \text { Ss } & \text { consonant lengthening } \\ / & \text { short pause }(0.5 \text { seconds) } \\ / / & \text { long pause }(0.5-1.5 \text { seconds) } \\ \left(n^{\prime \prime}\right) & n \text { seconds pause } \\ {[\quad]} & \text { turn overlapping with similarly marked turn } \\ = & \text { continuation of utterance after overlapping } \\ ()^{*} & \text { low talking / murmuring } \\ \left(()^{*}\right) & \text { non-understandable fragment } \\ \{\mathrm{xxx}\} & \text { researcher's comments } \\ \uparrow & \text { rising intonation } \\ \downarrow & \text { falling intonation } \\ - & \text { self interruption } \\ \& & \text { latched utterances }\end{array}$

